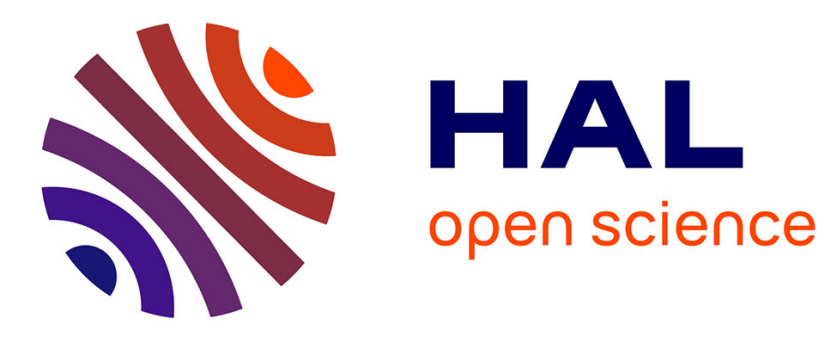

\title{
Why Polysemy Supports Radical Contextualism
}

\author{
François Recanati
}

\section{To cite this version:}

François Recanati. Why Polysemy Supports Radical Contextualism. Patrick Brézillon; Roy Turner; Carlo Penco. Modeling and Using Context, Springer, pp.216-222, 2019, 10.1007/978-3-030-349745_18. hal-02932361

\section{HAL Id: hal-02932361 https://hal.science/hal-02932361}

Submitted on 7 Sep 2020

HAL is a multi-disciplinary open access archive for the deposit and dissemination of scientific research documents, whether they are published or not. The documents may come from teaching and research institutions in France or abroad, or from public or private research centers.
L'archive ouverte pluridisciplinaire HAL, est destinée au dépôt et à la diffusion de documents scientifiques de niveau recherche, publiés ou non, émanant des établissements d'enseignement et de recherche français ou étrangers, des laboratoires publics ou privés. 


\section{Why Polysemy Supports Radical Contextualism}

François Recanati

Collège de France

In G. Bella and P. Bouquet (eds.), Context 2019, Berlin: Springer, 2019, pp. 1-7

\section{Meaning and content}

I take content to be fundamentally a property of mental states or acts (e.g. belief or judgment) and derivatively of speech acts. Consider someone who believes that elephants have wings, and expresses that belief by saying that elephants have wings. The proposition that elephants have wings is the content of her belief, as well as the content of the assertion she makes when she expresses that belief linguistically.

I take meaning to be a property of linguistic expressions (considered as types). The sentence 'Elephants have wings' has a certain meaning, and the words in that sentence do as well.

I take the debate between Literalism and Contextualism to bear on the relation between meaning and content. Literalism holds that they are the same thing. It accepts what I call the basic equation:

The basic equation:

meaning $=$ content

Contextualism is the opposite view. It rejects the basic equation.

Because it accepts the basic equation, Literalism takes the meaning of the sentence-type 'Elephants have wings' to be the proposition that elephants have wings. The meaning of subsentential constituents is taken to be their contribution to the meaning/content of the sentences in which they occur, i.e. objects, properties, relations etc. or modes of presentation thereof.

\section{Indexicals}

Indexicals constitute an obvious counter-example to the basic equation. Their linguistic meaning is not the same thing as their content. Their linguistic meaning is invariant, while their content is contextually variable (whether we take that content to be an object or a Fregean sense). In Kaplan's influential framework, the meaning of an indexical is a 'character' that determines the content carried by the indexical in context.

Indexicals are not sufficient to arbitrate the debate between Literalism and Contextualism, however. They are not sufficient because Literalists acknowledge that indexicals constitute an exception to the Basic Equation. In the case of indexicals, meaning $\neq$ content. Literalists accept that. Still, they maintain the basic equation as the default, while Contextualists reject the basic equation, even construed as the default. 


\section{From Literalism to Methodological Contextualism}

Contextualism comes in several varieties. I distinguish between methodological and substantial forms of Contextualism, and between two substantial forms of Contextualism (Figure 1).

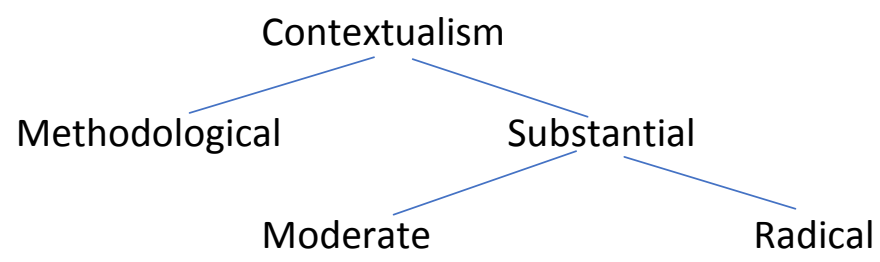

Figure 1. Varieties of Contextualism

The weakest form of Contextualism is Methodological Contextualism. It contrasts with Literalism in the following manner. Literalists take the indexical exception to be wellcircumscribed: there is a list of expressions known to be indexical (the so-called 'basic set'), ${ }^{1}$ and for the expressions that are not in that list the basic equation holds. So the default is: meaning = content (unless we are dealing with an expression in the list). According to Methodological Contextualism, however, we don't know in advance which expressions are indexical and which aren't. Ahead of inquiry, we should assume (by default) that meaning $\neq$ content, for indexicality is always a possibility. So Methodological Contextualism reverses what Literalism takes to be the default. ${ }^{2}$

\section{Substantial forms of Contextualism}

In its substantial forms, Contextualism considers that indexicals are not an 'exception': context-sensitivity generalizes to all expressions (whether indexical or not). All expressions are such that the content they contribute depends upon the context, in contrast to the (invariant) linguistic meaning of the expression.

There are two forms of Contextualism that count as substantial by my characterization. One is moderate, the other radical. Each appeals to a particular phenomenon. Moderate Contextualism appeals to the phenomenon of modulation, while Radical Contextualism to the phenomenon of polysemy.

\section{Moderate Contextualism}

The meaning of an indexical is gappy and calls for a contextual process of saturation (e.g. an assignment of values to free variables in logical form). That process is mandatory: without saturation, no content can be assigned to an indexical expression. According to Moderate

\footnotetext{
${ }^{1}$ The expression 'basic set' comes from Cappelen and Lepore 2005.

${ }^{2}$ On Methodological Contextualism, see Recanati 1994 and 2004:00.
} 
contextualism, however, there is another contextual process that takes place on the way from meaning to content: modulation.

Modulation covers processes of sense extension (loosening/broadening) and sense narrowing (enrichment) as well as semantic transfer (metonymy) and possibly other phenomena (see Recanati 2004 for an overview). It is hard to deny that a sentence like 'The ham sandwich stinks' carries distinct truth-conditional contents depending on whether the description is taken literally as referring to the sandwich or metonymically as referring to the person who ordered it. Similarly, 'John is crazy' carries distinct truth-conditions when 'crazy' is taken literally and when it is a hyperbole. So context-sensitivity generalizes: Just as the content of an indexical depends upon the context of use, the content actually carried by an ordinary, non indexical expression also depends upon the context: it depends on whether, and how, the literal meaning of the expression is 'modulated' in context.

\section{Radical Contextualism}

What makes moderate contextualism moderate is the fact that, in contrast to saturation, modulation is optional: it may or may not take place. Whether or not it takes place depends upon the context, so the possibility of 'zero-modulation' (Recanati 2010) is compatible with the generalization of context-sensitivity characteristic of substantial contextualism.

Cases of zero-modulation correspond to literal language use. In such cases, the basic equation still holds: meaning = content. According to radical contextualism, however, meaning is never identical to content. Lexical meaning is constitutively unable to figure as a constituent of content ; it does not have the proper format for that ('wrong format view'). This is where polysemy comes into the picture.

\section{Polysemy as ambiguity}

As soon as an expression comes into public use, it becomes polysemous - the more frequent its use, the more polysemous it is. The senses of a polysemous expression result from pragmatic modulation (one sense is a modulation of another) but these modulations have become conventionalized and the senses of a polysemous expression are stored in the memory of language users.

Since the senses of a polysemous expression are conventionalized (in contrast to novel instances of modulation), it is tempting to construe polysemous expressions as straightforwardly ambiguous (Fig. 2).

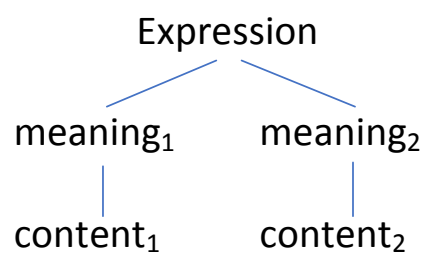

Figure 2. The ambiguity model 
Ambiguous expressions contribute different contents in different contexts, but this does not threaten the literalist equation of meaning and content (since ambiguous expressions possess distinct meanings).

\section{Objection: Polysemy vs homonymy}

Two homonymous expressions (e.g. 'bank' and 'bank') are different expressions, with the same phonological realization but distinct meanings. A polysemous expression is supposed to be something else. A polysemous expression admittedly carries distinct senses, but these senses are felt as related: they form a family of senses. So instead of two different expressions with the same shape but distinct meanings (homonymy), what we seem to have is a single expression, i.e. a semantic as well as a phonological unit (polysemy): The expression has a single meaning which (depending on one's theory) either accounts for, or supervenes on, the diversity of its conventional uses. If we don't allow polysemous expressions such an inherent meaning, distinct from the various senses they contribute in context, we are bound to deny that there is a difference between polysemy and homonymy. In other words : either polysemy does not exist (as a phenomenon distinct from homonymy), or, if it exists, it cannot be accounted for along the lines of the ambiguity model.

I call the alternative model we need the 'context-sensitivity model' because it posits a single meaning to which there correspond different contents in different contexts (as in the case of indexicals).

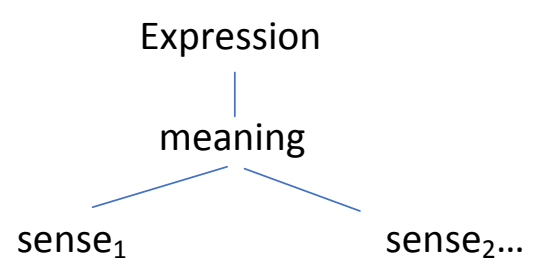

Figure 3. The context-sensitivity model

\section{What is the unitary meaning of a polysemous expression?}

For Ruhl (1989), polysemous words possess a highly abstract (and underspecified) meaning which they carry in all their occurrences and which is responsible for the various senses they contextually express. Because the underspecified meaning lies below the level of consciousness, what intuitions reveal (and dictionaries record) are the expressed senses. These senses depend on context (both linguistic and extralinguistic), while 'a word's semantics should concern what it contributes in all contexts' (Ruhl 1989 : 87). The task of the theorist is to discover lexical meaning by extracting from the data some abstract, unitary schema which all the uses fit.

I see two problems with this approach. First, it's not clear how it handles metonymies (which Ruhl hardly mentions). Second, even though polysemous expressions are conventionally associated with determinate senses which they regularly convey, these senses are not an aspect of the linguistic meaning of the expression, in Ruhl's framework. (The linguistic 
meaning is more abstract than these senses.) This is similar to the idea, floated in the seventies, that there are 'conventions of use' that are not 'meaning conventions' : e.g. the convention that 'Can you pass the salt ?' is a request that should be complied with rather than a question that should be answered. ${ }^{3}$ But this construal of 'meaning' is overly narrow. As Langacker emphasizes, our goal as meaning theorists should be 'to properly characterize a speaker's knowledge of linguistic convention'. Now,

A lexical item of frequent occurrence displays a substantial, often impressive variety of interrelated senses and conventionally sanctioned usages... Even when all its attested values are plausibly analysed as instantiations of a single abstract schema, or as extensions from a single prototype, there is no way to predict from the schema or prototype alone precisely which array of instantiations or extensions - out of all the conceivable ones - happen to be conventionally exploited within the speech community. (Langacker 1987 : 370)

Following Langacker, ${ }^{4}$ therefore, I take the meaning of a polysemous expression to be neither a 'prototype' nor an 'all-subsuming superschema', but the network of senses the expression is conventionally associated with (including the prototype and/or the superschema, should there be any, as well as the modulation relations between the senses).

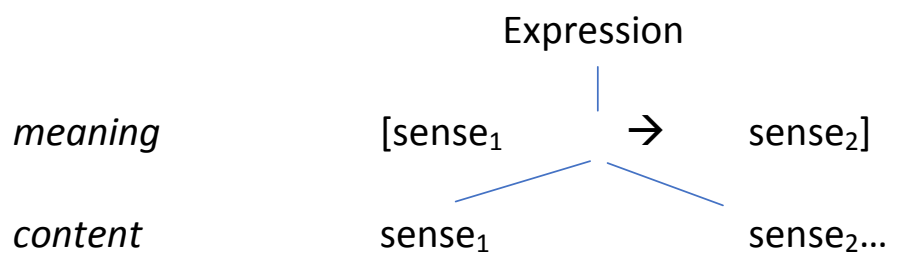

Figure 4. The network model

\footnotetext{
${ }^{3}$ See Searle 1975 and especially Morgan 1978.

4 "A strict reductionist approach would seek maximum economy by positing a single structure to represent the meaning of a lexical category. However, if our goal is to properly characterize a speaker's knowledge of linguistic convention, any such account is unworkable. From neither the category prototype alone, nor from an all-subsuming superschema (should there be one), is it possible to predict the exact array of extended or specialised values conventionally associated with a lexeme (out af all those values that are cognitively plausible). A speaker must learn specifically, for instance, that run is predicated of people, animals, engines, water, hosiery, noses, and candidates for political office ; the conventions of English might well be different. Equally deficient is the atomistic approach of treating the individual senses as distinct and unrelated lexical items. The claim of massive homonymy implied by such an analysis is simply unwarranted - it is not by accident, but rather by virtue of intuitively evident relationships, that the meanings are symbolized by the same form. A network representation provides all the necessary information : an inventory of senses describing the expression's conventional range of usage ; the relationships these senses bear to one another; schemas expressing the generalizations supported by a given range of values ; and specifications of distance and cognitive salience." (Langacker 1991 : 268)
} 
As can be seen by comparing Figure 4 with Figures 2 and 3, the network model blends features from the ambiguity model and the context-sensitivity model.

\section{Conversion into sense}

In language use, senses multiply and diversify through modulation operations, which are optional in the sense of context-driven. Think of the first time the word 'swallow' was used to refer to what an ATM sometimes does with credit cards. The sense of 'swallow' was then creatively extended so as to exploit the similarity between the ATM situation and ordinary swallowing-situations. What was extended (the input to modulation) was the standard sense of 'swallow' as it applies to living organisms with a digestive system. The output of modulation was the (broadened) sense in which an ATM can be said to swallow a credit card. As a result of conventionalization, the extended sense has become part of the network of senses which makes up the lexical meaning of 'swallow', but the modulation relation between the extended sense and the prototypical sense is still alive in the consciousness of the language users. So we must distinguish between three things:

(i) the lexical meaning of 'swallow', which has the wrong format for being a constituent of content (it is or comprises a network of senses);

(ii) the standard/literal/prototypical sense of 'swallow' (with respect to living organisms), which was the input to modulation in the ATM example; and

(iii) the extended sense relevant to ATMs, which was, and is still perceived as, the output of modulation.

On that view there is a principled difference between the linguistic meaning of a polysemous expression and the sense the expression contributes when used in context (even the standard or prototypical sense, should there be any). Context-sensitivity thus generalizes in a way which supports Radical Contextualism. An expression cannot directly contribute its lexical meaning, which has the 'wrong format' for being a constituent of content. The lexical meaning must be contextually converted into an appropriate sense through various context-sensitive operations (typically a mixture of sense selection and modulation).

\section{Conclusion: three types of contextual process}

We must distinguish the relation between the lexical meaning of 'swallow' and the extended sense the word takes in ATM-situations, namely a special case of conversion into sense, from the relation between that extended sense and the standard, prototypical sense of 'swallow', namely modulation. That distinction tends to be neglected because it is often (wrongly) assumed that the lexical meaning of 'swallow' is its standard/prototypical sense. But the distinction between modulation and conversion into sense is important because conversion into sense is mandatory, while modulation is optional. This makes conversion into sense similar to saturation (and polysemy similar to indexicality). Still, conversion into sense concerns all expressions (to the extent that, to a greater or lesser degree, all expressions are polysemous). This makes it similar to modulation (which may affect any expression), while saturation only concerns indexical expressions. 
In terms of these two features - mandatoriness and universality - we can characterize the three contextual processes that map meaning to content:

$$
\text { Mandatory Universal }
$$

Saturation
Modulation
Conversion into sense

Figure 5. Saturation, modulation, and conversion into sense

\section{References}

Cappelen, H. and Lepore, E. (2005) Insensitive Semantics. Oxford: Blackwell.

Benveniste, Emile (1966) Problèmes de Linguistique Générale, vol. I. Paris : Gallimard.

Benveniste, Emile (1974) Problèmes de Linguistique Générale, vol. II. Paris : Gallimard.

Kaplan, D. (1989) Demonstratives

Langacker, Ronald (1987) Foundations of Cognitive Grammar, vol. 1. Palo Alto : Stanford

University Press.

Langacker, Ronald (1991) Concept, Image and Symbol. Berlin : Mouton De Gruyter. Morgan, Jerry (1978). Two Types of Convention in Indirect Speech Acts. Syntax and Semantics 9: 261-80

Recanati, François (1994) Contextualism and Anti-Contextualism

Recanati, François (2004) Literal Meaning. Cambridge : Cambridge University Press.

Recanati, François (2010) Truth-Conditional Pragmatics. Oxford : Oxford University Press. Ruhl, Charles (1989) On Monosemy: A Study in Linguistic Semantics. Albany, N.Y. : State University of New York Press.

Searle, John (1975) Indirect Speech Acts. Syntax and Semantics 3: 59-82. 